СОСУДИСТЫЕ КОНФЛИКТЫ В АНДРОЛОГИИ. ЧАСТЬ 2. АРТЕРИОВЕНОЗНЫЕ КОНФЛИКТЫ НИЖНЕГО УРОВНЯ

(C) A.A. Kaпmo ${ }^{1,2,3}$, 3.В. Смыслова ${ }^{1,2}$

${ }^{1}$ АНО ДПО «Центр обучения медицинских работников», Москва;

${ }^{2}$ ФГАОУ ВО «Российский университет дружбы народов» Министерства науки и высшего образования

Российской Федерации, Москва;

${ }^{3}$ Многопрофильный медицинский холдинг «СМ-Клиника», Москва

Для цитирования: Капто А.А., Смыслова 3.В. Сосудистые конфликты в андрологии. Часть 2. Артериовенозные конфликты нижнего уровня // Урологические ведомости. - 2019. - Т. 9. - № 3. - С. 49-56. https://doi.org/10.17816/uroved9349-56

Поступила: 02.07.2019

Одобрена: 05.08.2019

Принята к печати: 19.09.2019

В настоящей работе проведен обзор литературы по распространенности, классификации, симптоматике, диагностике и лечению артериовенозных конфликтов нижнего уровня. Рассмотрены новые подходы в лечении как самих артериовенозных конфликтов, так и коморбидных заболеваний, таких как варикоцеле, варикозная болезнь вен органов малого таза, веногенная эректильная дисфункция, синдром хронической тазовой боли. Данные, представленные в статье, могут стать основанием для пересмотра подходов к ведению пациентов с варикоцеле, эректильной дисфункцией и хроническим рецидивирующим простатитом. Показано, что выполнение рентгенохирургической эмболизации вен простатического сплетения отдельно или в комбинации с эмболизацией яичковой вены и ангиопластикой и стентированием подвздошной вены возможно только на стыке урологии, андрологии и рентгенохирургии.

Ключевые слова: синдром щелкунчика; синдром Мея - Тюрнера; варикоцеле; варикозная болезнь вен органов малого таза.

\title{
VASCULAR CONFLICTS IN ANDROLOGY. PART 2. LOWER LEVEL ARTERYOVENOUS CONFLICTS
}

(C) A.A. Kapto ${ }^{1,2,3}$, Z.V. Smyslova ${ }^{1,2}$

${ }^{1}$ Education Center of Medical Workers, Moscow, Russia;

${ }^{2}$ RUDN University of the Ministry of Science and Higher Education of the Russian Federation, Moscow, Russia; ${ }^{3}$ Multidisciplinary Medical Holding "SM-Clinic", Moscow, Russia

For citation: Kapto AA, Smyslova ZV. Vascular conflicts in andrology. Part 2. Lower level arteryovenous conflicts. Urologicheskie vedomosti. 2019;9(3):49-56. https://doi.org/10.17816/uroved9349-56

Received: 02.07.2019

Revised: 05.08.2019

Accepted: 19.09 .2019

This paper presents a review of the literature on the prevalence, classification, symptoms, diagnosis and treatment of lower level arteriovenous conflicts. New approaches in the treatment of both arteriovenous conflicts and comorbid diseases such as varicocele, varicose veins of the pelvic organs, venogenic erectile dysfunction, chronic pelvic pain syndrome are presented. The data of the literature review can form the basis for the revision of approaches to the management of patients with varicocele, erectile dysfunction and chronic recurrent prostatitis. It is shown that x-ray surgical embolization of prostatic plexus veins alone or in combination with testicular vein embolization, angioplasty and iliac vein stenting is possible only at the junction of urology, andrology and x-ray surgery.

Keywords: Nutcracker syndrome; May-Thurner syndrome; varicocele; pelvic varicose disease.

\section{СИНДРОМ ПОДВЗДОШНОЙ ВЕНОЗНОЙ КОМПРЕССИИ}

Сдавление левой общей подвздошной вены между правой общей подвздошной артерией и 5-м поясничным позвонком и фиброзные спай- ки в ней впервые были описаны немецким патологом R. Virchow в 1851 г. [1]. R. Virchow отмечал, что глубокие илеофеморальные тромбозы встречались слева в 5 раз чаще, чем справа. Фиброзные спайки (шварты) в компрессированной подвздошной 


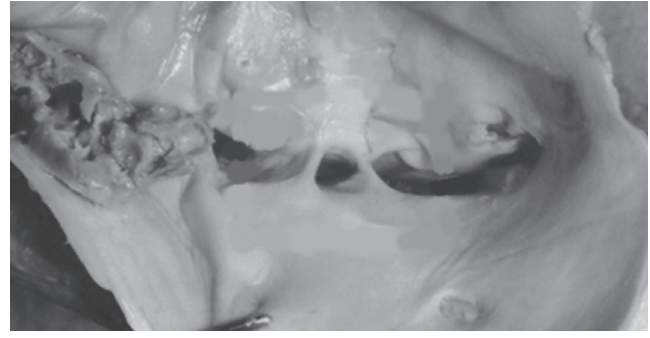

Рис. 1. Шварты (синехии, спайки) в просвете левой общей подвздошной вены по Н. Mitsuoka et al. (2013)

Fig. 1. Synechiae (adhesions) in the lumen of the left common iliac vein according to H. Mitsuoka et al. (2013)

вене являются неизбежным патогенетическим звеном этого заболевания (рис. 1).

В англоязычной литературе синдром сдавления левой общей подвздошной вены чаще называют May-Thurner Syndrome (синдромом Мея-Тюрнера). Правосторонний синдром Мея-Тюрнера был впервые описан R.M. Burke et al. (2006) у 62-летней пациентки, у которой в течение 4 лет отмечались глубокие венозные тромбозы с тромбоэмболией легочной артерии, вследствие чего ей был установлен фильтр в нижнюю полую вену [2].

\section{РАСПРОСТРАНЕННОСТЬ}

В 1908 г. J.P. McMurrich выявил обструкцию левой общей подвздошной вены в 31,25 \% случаев при проведении 32 аутопсий [3] и в 30 \% случаев при проведении 57 аутопсий [4]. В 1943 г. W.E. Ehrich и E.B. Krumbhaar при выполнении 412 аутопсий обнаружили обструкцию левой общей подвздошной вены в 23,8 \% случаев, в 4 \% случаев отметили возможную ее незначительную обструкцию, и в 1,8 \% случаев наблюдались другие изменения подвздошных вен [5]. R. Мау и J. Thurner в 1957 г. при аутопсии 430 трупов выявили прижатие левой общей подвздошной вены правой общей подвздошной артерией к телу 5-го позвонка в 19-22 \% случаев [6]. D. Negus et al. (1968) зарегистрировали обструкцию левой общей подвздошной вены в 14 \% случаев при обследовании 100 пациентов [7]. N. Usui et al. (1978) наблюдали гипертрофию tunica media и фиброзные спайки в левой общей подвздошной вене в 50 \% случаев при аутопсии 90 трупов и только у одного из них в правой общей подвздошной вене [8]. По данным H.C. Baron et al. (2000), бессимптомное сдавление левой общей подвздошной вены у взрослого населения встречается в 16-20 \% случаев [9].

Таким образом, подвздошная венозная компрессия является широко распространенной патологией.

\section{КЛАССИФИКАЦИЯ}

С точки зрения клинициста, компрессия подвздошных вен может быть тромботической и нетромботической. Ранее основное внимание врачей было направлено на диагностику и лечение тромботической компрессии.

Варианты нетромботической компрессии подвздошных вен (nonthrombotic iliac vein lesion, NIVL) были описаны S. Raju и P. Neglen в 2006 г. [10]. Авторы выделили четыре варианта артериовенозных конфликтов: 1) классическая левосторонняя проксимальная компрессия за счет сдавления левой общей подвздошной вены правой общей подвздошной артерией (Left Proximal NIVL); 2) правосторонняя проксимальная компрессия за счет сдавления правой общей подвздошной вены правой общей подвздошной артерией (Right Proximal NIVL); 3) левосторонняя дистальная компрессия за счет сдавления левой наружной подвздошной вены левой внутренней подвздошной артерией (Left Distal NIVL); 4) правосторонняя дистальная компрессия за счет сдавления правой наружной подвздошной вены правой общей подвздошной артерией (Right Distal NIVL). U.B. Jeon et al. (2010) предложили классификацию морфологических изменений левой общей подвздошной вены при синдроме Мея-Тюрнера: тип I - фокальная компрессия правой обшей подвздошной артерией, тип II - диффузная атрофия левой общей подвздошной вены, тип III - рубцовая облитерация левой общей подвздошной вены [11]. H. Mitsuoka et al. (2013) при аутопсии 28 трупов (12 мужчин и 16 женщин), средний возраст - 82,5 года, установили два варианта аномалий аорты по месту пересечения (перекрестка) правой общей подвздошной артерии: группа А - полное или частичное сдавление правой общей подвздошной артерией левой общей подвздошной вены (бифуркация аорты на нижнем уровне) у 19 (67,9 \%) из 28 трупов; группа В - правая общая подвздошная артерия сдавливает нижнюю полую вену (бифуркация аорты на высоком уровне) у 9 (32\%) [12]. R. Englund (2017) обследовал и пролечил 61 пациента с компрессией левой общей подвздошной вены и по результатам флебографии предложил свою классификацию, представленную в табл. 1 [13]. Автор также указал, что показанием к ангиопластике и стентированию являлась вторая стадия в $20 \%$ случаев, третья стадия - в $100 \%$, стадия $4 \mathrm{a}-$ в 71,4 \% и стадия $4 \mathrm{~b}-$ в $75 \%$ случаев.

Анализ данных МРТ нижней полой вены и сосудов малого таза и КТ органов брюшной полости 
Классификация подвздошной венозной компрессии по R. Englund (2017) [13] Classification of iliac venous compression according to R. Englund (2017) [13]

\begin{tabular}{|l|c|c|c|c|c|c|}
\hline \multicolumn{1}{|c|}{ Признаки } & Стадия 0 & Стадия 1 & Стадия 2 & Стадия 3 & Стадия 4а & Стадия 4b \\
\hline Компрессия & - & + & + & + & + & + \\
\hline Обструкция & - & - & + & + & + & + \\
\hline Коллатерализация & - & - & + & + & + & + \\
\hline Фиброзные спайки & - & $-/+$ & $-/+$ & + & + & + \\
\hline Смежный венозный сегмент & - & - & - & - & + \\
\hline $\begin{array}{l}\text { Дистальный венозный сегмент } \\
\text { (подколенный, бедренный) }\end{array}$ & - & - & - & + \\
\hline
\end{tabular}

Таблииа 2 / Table 2

Локализация илеофеморального стеноза по S.A. Rizvi et al. (2018) [15]

Localization of ileofemoral stenosis according to S.A. Rizvi et al. (2018) [15]

\begin{tabular}{|l|c|c|}
\hline \multicolumn{1}{|c|}{ Сегмент венозной системы } & Справа, \% & Слева, \% \\
\hline Проксимальный сегмент общей подвздошной вены & 24,3 & 42,6 \\
\hline Средний сегмент общей подвздошной вены & 11,3 & 27 \\
\hline Дистальный сегмент общей подвздошной вены & 7,8 & 1,6 \\
\hline Проксимальный сегмент наружной подвздошной вены & 24,3 & 7,4 \\
\hline Средний сегмент наружной подвздошной вены & 24,3 & 17,2 \\
\hline Дистальный сегмент наружной подвздошной вены & 6,1 & 1,6 \\
\hline Проксимальный сегмент общей бедренной вены & 1,7 & 2,5 \\
\hline
\end{tabular}

с контрастированием 225 пациентов с двусторонним варикоцеле, варикозной болезнью вен органов малого таза и синдромом Мея - Тюрнера в возрасте от 17 до 69 лет (в среднем - 33,8 года) позволил предложить топографо-анатомическую классификацию вариантов компрессии подвздошных вен [14]. Согласно данной классификации существует шесть вариантов компрессии: 1) центральный проксимальный - высокая бифуркация аорты, при которой правая общая подвздошная артерия сдавливает нижний отдел нижней полой вены до ее деления на подвздошные вены; 2) центральный дистальный - высокая бифуркация аорты, при которой правая общая подвздошная артерия сдавливает нижний отдел нижней полой вены в месте ее деления на подвздошные вены; 3) левый проксимальный - правая общая подвздошная артерия сдавливает левую общую подвздошную вену (синдром Мея-Тюрнера); 4) левый дистальный сдавление левой наружной и/или левой внутренней подвздошной артерией левой наружной подвздошной вены; 5) правый проксимальный - сдавление правой общей подвздошной артерией правой общей подвздошной вены; 6) правый дистальный - сдавление правой наружной и/или правой внутренней подвздошной артерией правой наружной подвздошной вены. S.A. Rizvi et al. (2018) с января 2013 по декабрь 2014 г. выполнили 268 ангиопластик и стентирований у 210 пациентов с бестромботической компрессией подвздошных вен. Двусторонняя установка стента была выполнена 58 пациентам; 173 (64,6 \%) операции были проведены у женщин [15]. При этом классический синдром Мея-Тюрнера встречался только в 42,6 \% случаев (табл. 2).

При обработке данных MPТ нижней полой вены и сосудов малого таза с 3D-реконструкцией, определяющих не локализацию, а выраженность подвздошной компрессии, мы пришли к решению о целесообразности выделения четырех стадий этого заболевания [16] (рис. 2).

При проведении илеокаваграфии мы выделили четыре стадии синдрома Мея - Тюрнера в зависимости от наличия и выраженности коллатерального кровообращения (рис. 3) [16].

\section{Клинические проявления}

Естественное течение синдрома компрессии подвздошной вены служит предпосылкой к развитию илеофеморального тромбоза. В 1965 г. F.B. Cockett и M.L. Thomas описали 35 пациентов с илеофеморальным тромбозом в сочетании с компрессией подвздошной вены. Развернутую клиническую картину 


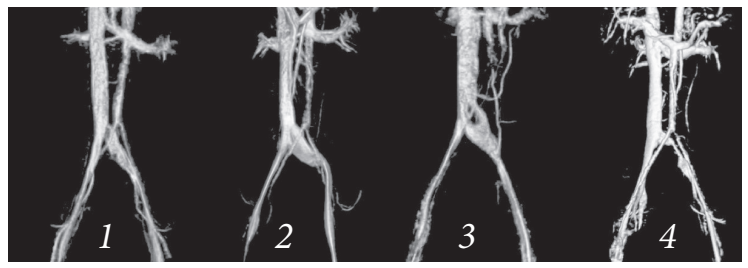

Рис. 2. Стадии синдрома подвздошной венозной компрессии (синдрома Мея-Тюрнера) по данным МРТ нижней полой вены и сосудов малого таза с 3D-реконструкцией по А.А. Капто (2018): 1 -я стадия компрессия левой общей подвздошной вены; 2-я стадия - компрессия левой общей подвздошной вены с ее дилатацией; 3 -я стадия компрессия левой подвздошной вены со смыканием стенок сосуда в центральной его части и с ее дилатацией; 4-я стадия - выраженное и протяженное сужение просвета левой общей подвздошной вены

Fig. 2. Stages of the ileal venous compression syndrome (May-Thurner Syndrome) according to MRI of the vena cava inferior and pelvic blood vessels with 3D reconstruction according to A.A. Kapto (2018): stage 1 - compression of the left common iliac vein; stage 2 - compression of the left common iliac vein with its dilatation; stage $3-$ compression of the left iliac vein with the closure of the vessel walls in its central part and with its dilatation; stage 4 - pronounced and extended narrowing of the left common iliac vein lumen
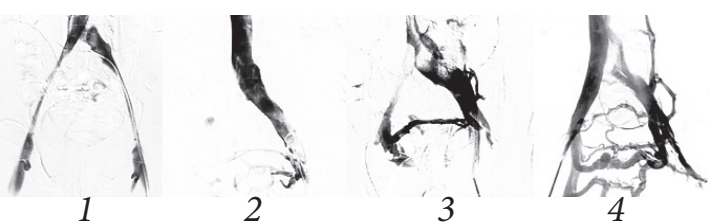

Рис. 3. Стадии синдрома Мея - Тюрнера по данным илеокаваграфии в зависимости от наличия и выраженности коллатерального кровообращения по А.А. Капто (2018): 1 - отсутствие контрастирования вен таза; 2 - контрастирование вен таза; 3 - контрастирование вен таза с перетоком контраста в контралатеральную правую общую подвздошную вену; 4 - контрастирование вен таза с перетоком контраста в правую общую подвздошную вену и восходящие поясничные вены слева

Fig. 3. Stages of May-Thurner syndrome according to ileocavagraphy depending on the presence and intensity of collateral circulation according to A.A. Kapto (2018): 1 - lack of contrast in the pelvic veins; 2 - contrasting of the pelvic veins; 3 - contrasting of the pelvic veins with the flow of contrast into the contralateral right common iliac vein; $4-$ contrasting of the pelvic veins with the flow of contrast into the right common iliac vein and ascending lumbar veins on the left

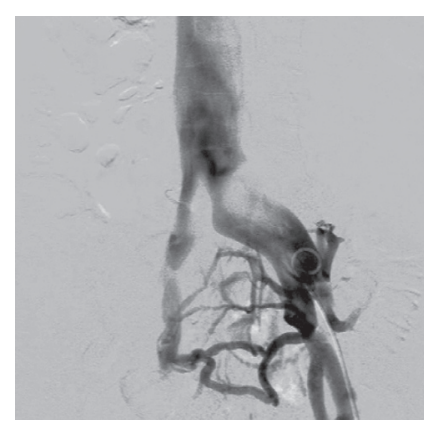

Рис. 4. Антеградная илеокаваграфия. Нетромботическая компрессия левой почечной вены. Коллатеральное кровообращение и выраженное венозное полнокровие органов малого таза

Fig. 4. Antegrade ileocavagraphy Non-thrombotic compression of the left renal vein. Collateral circulation and pronounced venous congestion of the pelvic organs

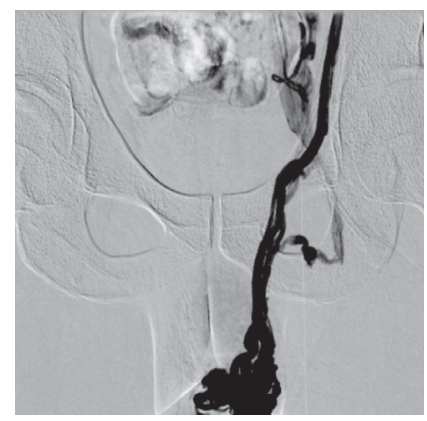

Рис. 5. Ретроградная флеботестикулография пациента с Nutcracker syndrome и синдромом Мея - Тюрнера. Контрастирование левой общей подвздошной вены через кремастерную вену

Fig. 5. Retrograde phlebotesticulography of a patient with Nutcracker syndrome and MayThurner syndrome. Contrasting the left common iliac vein through the cremaster vein илеофеморального тромбоза у пациентов с синдромом сдавления подвздошной вены называют Cockett Syndrome, по фамилии автора, давшего описание клинической картины заболевания $[17,18]$.

Гипертензия в бассейне левой общей подвздошной вены вследствие ее компрессии между правой общей подвздошной артерией и телом пятого поясничного позвонка (синдром Мея - Тюрнера) является причиной венозного полнокровия органов малого таза (рис. 4) и ретроградного кровотока по вене мышцы, поднимающей яичко в гроздевидное сплетение яичка и его придатка (илеосперматический тип варикоцеле) (рис. 5).

B.L. Coolsaet (1980) представил результаты ангиографического обследования 67 пациентов с левосторонним варикоцеле [19]. С помощью венографии почек, внутренней яичковой и общей подвздошной вен было выделено три типа варикоцеле: 1) во внутренней яичковой вене; 2) в экстрафуникулярных венах, что было вызвано обструкцией общей подвздошной вены, куда они впадают; 3) в обоих системах одновременно (рис. 6).

А.И. Неймарк и др. (2013) предложили выделять варикоцеле двух видов: 1) изолированное варикоцеле с минимальными нарушениями гемодинамики в правом семеннике без вовлечения в патологический процесс предстательной железы; и 2) варикоцеле в сочетании с тазовой конгестией, при котором нарушения затрагивают не только левое яичко, но и контралатеральный семенник и предстательную железу [20].

Как при Nutcracker syndrome, так и при синдроме Мея-Тюрнера отмечается венозное полнокровие простатического сплетения. При синдроме Мея-Тюрнера развивается, как правило, двустороннее варикоцеле, а по данным ТРУЗИ визуализируется билатеральное расширение вен простатического сплетения (рис. 7).

\section{Диагностика}

Диагноз варикозной болезни вен органов малого таза верифицируют при помощи ТРУЗИ при наличии следующих критериев: расширения вен парапростатического сплетения более 5 мм и/или наличия рефлюкса крови при пробе Вальсальва при дуплексном ангиосканировании [21]. В 2017 г. нами предложена классификация варикозного расширения вен простаты (табл. 3) [22].

Синдром подвздошной венозной компрессии верифицируют по данным МРТ нижней полой вены или сосудов малого таза и КТ органов брюшной полости с контрастным усилением, флебографии, флебо- 
тонометрии, внутрисосудистого УЗИ. При обработке данных МРТ нижней полой вены и сосудов малого таза и КТ органов брюшной полости с контрастным усилением определяют критерии подвздошной венозной (вертеброартериальной) компрессии, которые включают в себя определение величины нижнего люмбарного лордозного угла (Lower lumbar lordosis angle, LLLA) (норма - 134,33-136,76 ) и диаметра подвздошного венозного туннеля (Diameter of the iliac vein tunnel, IVTD) (норма - 4,18-4,50 мм) [23].

Диагноз веногенной эректильной дисфункции верифицируют при помощи вопросника МИЭФ-5, ультразвуковой фармакодоплерографии полового члена и динамической фармакокавернозографии.

\section{Лечение}

Лечение синдрома компрессии левой подвздошной вены (синдрома Мея - Тюрнера) проводят рентгенохирургическими методами, оно включает в себя следующие этапы: 1) пункцию вены (бедренной, подколенной); 2) мультипроекционную интраоперационную флебографию, показывающую коллатеральное кровообращение левой общей подвздошной вены; 3) баллонную ангиопластику левой общей подвздошной вены; 4) имплантацию стента в левую общую подвздошную вену; 5) постдилатацию стентированного сегмента; 6) контрольную флебографию, показавшую проходимость левой общей подвздошной вены и отсутствие коллатерального кровообращения.

Рентгенохирургическую ангиопластику и стентирование подвздошных вен при лечении тромботической болезни применяют в течение последних трех десятилетий [24-27]. Рентгенохирургическую ангиопластику и стентирование подвздошных вен при лечении рецидивного варикоцеле и варикозной болезни вен органов малого таза у мужчин (синдром хронической тазовой боли, веногенная эректильная дисфункция, хронический простатит) стали использовать с 2017 г. [28, 29].

Показаниями к ангиопластике и стентированию подвздошных вен у андрологических пациентов являются: 1) выраженные симптомы со стороны тазовых органов (боль, дизурия, эректильная дисфункция); 2) двустороннее и/или рецидивное варикоцеле; 3) варикозное расширение вен предстательной железы II-III степени (максимальный диаметр вен простатического сплетения $>5$ мм); 4) компрессия подвздошных вен по данным МРТ и флебографии; 5) коллатеральное кровообращение под-
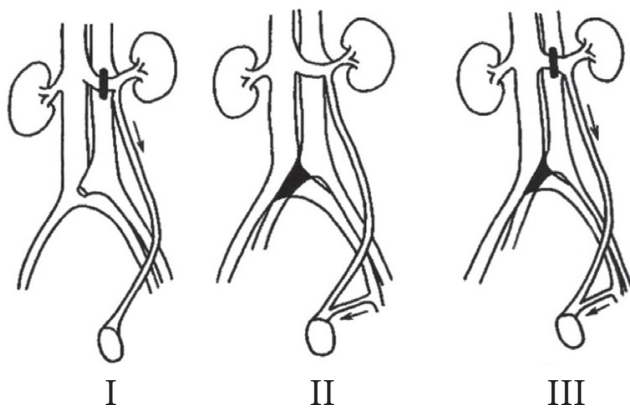

III

Рис. 6. Классификация варикоцеле по B.L. Coolsaet (1980): I — peносперматический тип; II - илеосперматический тип; III - смешанный тип

Fig. 6. Classification of varicocele according to B.L. Coolsaet (1980): I - renospermic type; II - ileospermic type; III - mixed type

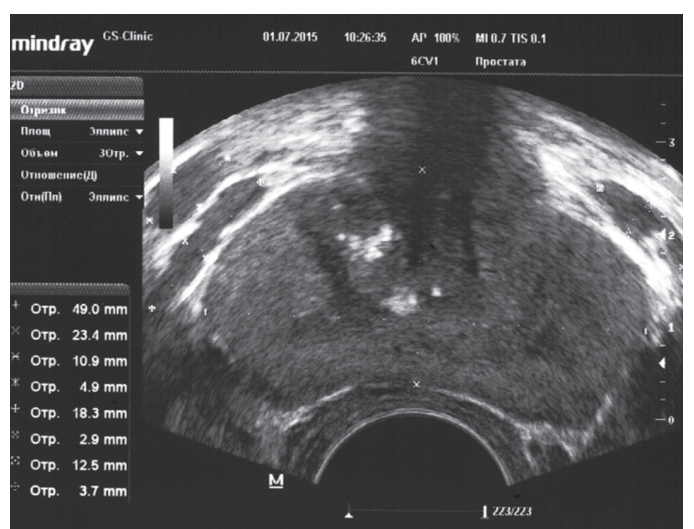

Рис. 7. ТРУЗИ простаты пациента К., 33 года, с двусторонним варикоцеле 3 -й стадии при синдроме Мея - Тюрнера. Объем проста-


справа - 12,5 мм. Хронический калькулезный простатит

Fig. 7. Transrectal ultrasound imaging of the prostate of patient K., 33 years old, with bilateral stage 3 varicocele and May-Thurner syndrome. Prostate volume $-22.3 \mathrm{~cm}^{3}$. The maximum diameter of the veins on the left is 10.9 and $18.3 \mathrm{~mm}$, on the right $-12.5 \mathrm{~mm}$. Chronic calculous prostatitis

Таблиия 3 / Table 3

Ультразвуковая классификация варикозного расширения вен простаты по А.А. Капто (2017) [22]

Ultrasound classification of varicose veins of the prostate according to A.A. Kapto (2017) [22]

\begin{tabular}{|c|l|c|c|c|}
\hline $\begin{array}{c}\text { Ста- } \\
\text { дия }\end{array}$ & $\begin{array}{c}\text { Стадия } \\
\text { варикоза }\end{array}$ & $\begin{array}{c}\text { Макси- } \\
\text { мальный } \\
\text { диаметр } \\
\text { вен, мм }\end{array}$ & $\begin{array}{c}\text { Скорость } \\
\text { кровотока, } \\
\text { см/с }\end{array}$ & $\begin{array}{c}\text { Скорость } \\
\text { кровотока при } \\
\text { пробе Валь- } \\
\text { сальвы, см/с }\end{array}$ \\
\hline 1-я & Видимый & $<4$ & $<3$ & $<5$ \\
\hline $2-я$ & Значимый & $5-10$ & $3-5$ & $5-15$ \\
\hline $3-я$ & $\begin{array}{l}\text { Выражен- } \\
\text { ный }\end{array}$ & $>10$ & $>5$ & $>15$ \\
\hline
\end{tabular}

вздошных вен по данным флебографии; 6) градиент давления в участках дистальнее и проксимальнее стеноза по данным прямой флебоманометрии не менее 4 мм рт. ст.; 7) патоспермия и бесплодие как следствие илеосперматического типа варикоцеле. С марта 2017 по май 2019 г. мы выполнили 
Таблица 4 / Table 4 Методы эмболизации вен простатического сплетения (с указанием авторов, впервые выполнивших операцию) Methods of embolization of the veins of the prostatic plexus (indicating authors who first performed operation)

\begin{tabular}{|l|l|l|l|}
\hline \multicolumn{3}{|c|}{ Рентгенохирургическая эмболизац простатического сплетения } \\
\hline \multicolumn{3}{|c|}{ Антеградная } & \multicolumn{2}{c|}{ Ретроградная } \\
\hline $\begin{array}{l}\text { Инцизия } \\
\text { v. dorsalis penis }\end{array}$ & $\begin{array}{l}\text { Пункция } \\
\text { v. dorsalis penis }\end{array}$ & $\begin{array}{l}\text { Доступ через v. femoralis } \\
\text { (трансфеморальный) }\end{array}$ & $\begin{array}{l}\text { Доступ через v. basilica } \\
\text { (трансбазилярный) }\end{array}$ \\
\hline $\begin{array}{l}\text { D. Maiza et al. (1984, 1985) } \\
\begin{array}{l}\text { (31, 32]; P. Courtheoux et al. } \\
(1985,1986)[33,34]\end{array}\end{array}$ & $\begin{array}{l}\text { J.J. Bookstein, A.L. Lurie } \\
\text { (1988) [35] }\end{array}$ & H.H. Schild et al. (1993) [36] & $\begin{array}{l}\text { А.А. Капто, А.Г. Коледин- } \\
\text { ский (2019) [37] }\end{array}$ \\
\hline
\end{tabular}
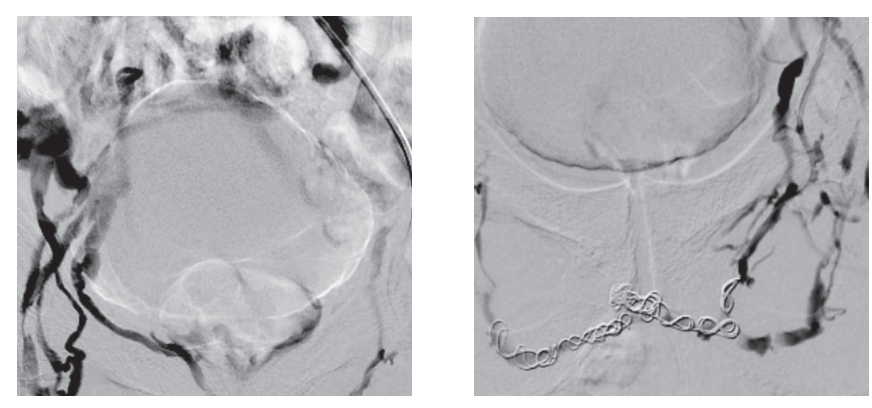

эндоваскулярную ангиопластику и стентирование 70 пациентам с подвздошной венозной компрессией, варикозной болезнью вен органов малого таза и двусторонним варикоцеле с положительным клиническим эффектом. Высокая клиническая эффективность рентгенэндоваскулярной ангиопластики и стентирования у пациентов с илеосперматическим типом варикоцеле и варикозной болезнью вен органов малого таза вследствие подвздошной венозной компрессии позволяет рекомендовать эту методику для применения в подобных случаях.

В настоящее время веногенная эректильная дисфункция не рассматривается как самостоятельное заболевание и, тем более, как следствие варикозного расширения дорзальной вены полового члена. Чаще всего она является следствием варикозной болезни вен органов малого таза. J.J. Keller et al. (2012) в результате анализа более 120000 историй болезни пришли к выводу, что эректильная дисфункция встречается в 5 раз чаще у пациентов с варикоцеле. При этом наибольшая распространенность эрекционных нарушений возникает в возрасте старше 60 лет. Предшествующее оперативное лечение по поводу варикоза вен семенного канатика, по мнению тайваньских исследователей, снижает риск развития расстройств эрекции почти в 2 раза [30]. Варикозная болезнь вен органов малого таза у мужчин, или синдром тазовой флебопатии, включает в себя следующие основные клинические проявления: 1) варикоцеле; 2) варикоз вен кожи мошонки, полового члена и нижних конечностей; 3) простатопатии (хронический простатит,
Рис. 8. Ретроградная рентгенохирургическая эмболизация простатического сплетения доступом через v. basilica (трансбазилярный доступ). Слева контрастируется простатическое венозное сплетение и кавернозные тела полового члена в месте патологического венозного дренажа, справа - отсутствие венозной утечки после эмболизации спиралями Gianturko (Cook Medical, USA)

Fig. 8. Retrograde X-ray guided surgical embolization of the prostatic plexus by access through v. basilica (transbasilar access). On the left, the prostatic venous plexus and cavernous bodies of the penis in the place of pathological venous drainage are contrasted, on the right - the absence of venous leakage after embolization with Gianturko spirals (Cook Medical, USA)

доброкачественная гиперплазия предстательной железы); 4) венозную недостаточность полового члена с развитием веногенной эректильной дисфункции; 5) геморрой; 6) хронический болевой синдром; 7) дизурию в форме обструктивной и/или ирритативной симптоматики [22]. Общепринятые методы оперативного лечения веногенной эректильной дисфункции в большинстве случаев не достаточно эффективны, поэтому этим пациентам чаще всего предлагают эндофаллопротезирование как последнюю возможность оптимизировать половую функцию. Альтернативным направлением в оперативном лечении веногенной эректильной дисфункции является рентгенохирургическая эмболизация вен простатического сплетения, которую стали применять во всем мире с 1984 г. Эффективность эмболизации вен простатического сплетения значительно превышает эффективность других операций при веногенной эректильной дисфункции, достигая, по данным литературы, в среднем 85 \% случаев. Все методы эмболизации по хирургическому доступу можно разделить на две группы: антеградную и ретроградную эмболизацию вен простатического сплетения (табл. 4).

Ретроградная рентгенохирургическая эмболизация простатического сплетения доступом через v. basilica (трансбазилярный доступ) является, с нашей точки зрения, более удобной, так как при ней отсутствует изгиб внутрисосудистого катетера в илеокавальном сегменте (рис. 8).

Новое перспективное направление лечения данной патологии представляют гибридные и комбини- 
рованные операции, позволяющие воздействовать как на причины веногенной эректильной дисфункции, так и на сформировавшийся в результате этих причин патологический венозный дренаж. Проведение рентгенохирургической эмболизации вен простатического сплетения отдельно или в комбинации с эмболизацией яичковой вены и с ангиопластикой и стентированием подвздошной вены возможно только на стыке урологии, андрологии и рентгенохирургии. Это обстоятельство определило целесообразность создания тематических курсов повышения квалификации врачей на кафедре урологии АНО ДПО «Центр обучения медицинских работников» с 2019 г.

\section{Дополнительная информация}

Конфликт интересов отсутствует.

Финансирования не проводилось.

Благодарности. Авторы выражают благодарность профессору Сальману Хасуновичу Аль-Шукри и профессору Игорю Валентиновичу Кузьмину за профессиональное и внимательное отношение к проблемам сосудистой андрологии.

Информация о вкладе каждого автора:

A.А. Капто - концепция и дизайн исследования, написание текста.

3.В. Смыслова - сбор и обработка материалов, оформление иллюстраций.

\section{ЛИТЕРАТУРА}

1. Virchow R. Über die Erweiterung kleinerer Gefäfse. Arch Path Anat. 1951;3:427-429. https://doi.org/10.1007/bf01960918.

2. Burke RM, Rayan SS, Kasirajan $\mathrm{K}$, et al. Unusual case of right-sided May-Thurner syndrome and review of its management. Vascular. 2006;14(1):47-50. https://doi.org/10.2310/6670.2006.00012.

3. McMurrich JP. The occurrence of congenital adhesions in the common iliac veins, and their relation to thrombosis of the femoral and iliac veins. Am J Med Sci. 1908;135(3):342-346. https://doi. org/10.1097/00000441-190803000-00004.

4. McMurrich JP. Congenital adhesions in the common iliac veins. Anat Record. 1906;1:78-79.

5. Ehrich WE, Krumbhaar EB. A frequent obstructive anomaly of the mouth of the left common iliac vein. Am Heart J. 1943;23: 737-750. https://doi.org/10.1016/s0002-8703(43)90285-6.

6. May R, Thurner J. The cause of the predominantly sinistral occurrence of thrombosis of the pelvic veins. Angiology. 1957;8(5): 419-427. https://doi.org/10.1177/000331975700800505.

7. Negus D, Fletcher EW, Cockett FB, Thomas ML. Compression and band formation at the mouth of the left common iliac vein. $\mathrm{Br} J$ Surg. 1968;55(5):369-374. https://doi.org/10.1002/bjs.1800550510.

8. Usui N, Muraguchi K, Yamamoto H, et al. [llium and femoral vein thrombosis. (In Japanese)]. Surgery. 1978;40:983.
9. Baron HC, Shams J, Wayne M. lliac vein compression syndrome: a new method of treatment. Am Surg. 2000;66(7):653-655

10. Raju S, Neglen P. High prevalence of nonthrombotic iliac vein lesions in chronic venous disease: a permissive role in pathogenicity. J Vasc Surg. 2006;44(1):136-43. https://doi.org/10.1016/j. jvs.2006.02.065.

11. Jeon UB, Chung JW, Jae HJ, et al. May-Thurner syndrome complicated by acute iliofemoral vein thrombosis: helical CT venography for evaluation of long-term stent patency and changes in the iliac vein. AJR Am J Roentgenol. 2010;195(3):751-757. https:// doi.org/10.2214/AJR.09.2793.

12. Mitsuoka $H$, Ohta $T$, Hayashi $\mathrm{S}$, et al. Histological study on the left common iliac vein spur. Ann Vasc Dis. 2014;7(3):261-265. https://doi.org/10.3400/avd.0a.14-00082.

13. Englund R. Towards a classification of left common iliac vein compression based on triplanar phlebography. Surgical Science. 2017;8:19-26. https://doi.org/10.4236/ss.2017.81003.

14. Капто А.А. Эндоваскулярная хирургия подвздошных вен при двустороннем варикоцеле и варикозной болезни вен органов малого таза у мужчин // Урологические ведомости. - 2018. T. 8. - № 1. - C. 11-17. [Kapto AA. Endovascular surgery of the iliac veins with bilateral varicocele and varicose veins of the pelvic organs in men. Urologicheskie vedomosti. 2018;8(1):11-17. (In Russ.)]. https://doi.org/10.17816/uroved8111-17.

15. Rizvi SA, Ascher E, Hingorani A, Marks N. Stent patency in patients with advanced chronic venous disease and nonthrombotic iliac vein lesions. J Vasc Surg Venous Lymphat Disord. 2018;6(4):457-463. https://doi.org/10.1016/j.jvsv.2018.02.004.

16. Капто А.А. Синдром Мея-Тернера и варикозная болезнь вен органов малого таза у мужчин // Андрология и генитальная хирургия. - 2018. - Т. 19. - № 4. - С. 28-38. [Kapto AA. May-Thurner syndrome and varicose veins of the pelvic organs in men. Andrology and genital surgery journal. 2018;19(4):28-38. (In Russ.)]. https:// doi.org/10.17650/2070-9781-2018-19-4-28-38.

17. Cockett FB, Thomas ML. The iliac compression syndrome. Br J Surg. 1965;52(10):816-821. https://doi.org/10.1002/bjs.1800521028.

18. Cockett FB. Venous causes of swollen leg. $\mathrm{Br} J$ Surg. 1967;54(10):891-894. https://doi.org/10.1002/bjs.1800541025.

19. Coolsaet BL. The varicocele syndrome: venography determining the optimal level for surgical management. J Urol. 1980;124(6): 833-839. https://doi.org/10.1016/s0022-5347(17)55688-8.

20. Неймарк А.И., Попов И.С., Газаматов А.В. Особенности микроциркуляции предстательной железы и гонад у юношей, страдающих изолированным варикоцеле и варикоцеле в сочетании с тазовой конгестией // Экспериментальная и клиническая урология. - 2013. - № 2. - С. 56-60. [Neymark Al, Popov IS, Gazamatov AV. The characteristics of the prostate and gonadal microcirculation in the adolescents with isolated varicocele and varicocele with the pelvic congestion. Experimental and clinical urology. 2013;(2):56-60. (In Russ.)] 
21. Цуканов А.Ю., Ляшев Р.В. Нарушение венозного кровотока как причина хронического абактериального простатита (синдрома хронической тазовой боли) // Урология. - 2014. - № 4. C. 33-38. [Tsukanov AYu, Lyashev RV. Disorders of venous blood flow as a cause of chronic abacterial prostatitis (chronic pelvic pain syndrome). Urologija. 2014;(4):33-38. (In Russ.)]

22. Капто А.А. Варикозная болезнь органов малого таза у мужчин // Диагностикаи лечение веногеннойэректильной диссфункции. Клиническое руководство / Под общей ред. проф. Д.Г. Курбатова. М.: Медпрактика-М; 2017. - С. 140-166. [Kapto AA. Varikoznaja bolezn' organov malogo taza u muzhchin. In: Diagnostika i lechenie venogennoj jerektil'noj disfunkcii. Klinicheskoe rukovodstvo. Ed by D.G. Kurbatov. Moscow: Medpraktika-M;2017.P. 140-166. (In Russ.)]

23. Ou-Yang L, Lu GM. Underlying anatomy and typing diagnosis of May-Thurner syndrome and clinical significance: an observation based on CT. Spine (Phila Pa 1976). 2016;41(21): E1284-E1291. https://doi.org/10.1097/BRS.0000000000001765.

24. Zollikofer CL, Largiader I, Bruhlmann WF, et al. Endovascular stenting of veins and grafts: preliminary clinical experience. Radiology. 1988;167(3):707-712. https://doi.org/10.1148/radiology.167.3.2966417.

25. Semba CP, Dake MD. lliofemoral deep venous thrombosis: aggressive therapy with catheter-directed thrombolysis. Radiology. 1994; 191(2):487-494. https://doi.org/10.1148/radiology.191.2.8153327.

26. Nazarian GK, Bjarnason H, DietzCAJr, etal. Iliofemoral venous stenoses: effectiveness of treatment with metallic endovascular stents. Radiology. 1996;200(1):193-9. https://doi.org/10.1148/radiology.200.1.8657909.

27. Binkert CA, Schoch E, Stuckmann G, et al. Treatment of pelvic venous spur (May-Thurner syndrome) with self-expanding metallic endoprostheses. Cardiovasc Intervent Radiol. 1998;21(1):22-26. https://doi.org/10.1007/s002709900205.

28. Капто А.А., Виноградов И.В., Харпунов В.Ф., Мамедов Р.Э. Рентгенэндоваскулярная ангиопластика и стентирование у мужчины при May-Thurner syndrome // Сборник тезисов 12-го Конгресса Профессиональной Ассоциации Андрологов России; 24-27 мая 2017. - Сочи, Дагомыс; 2017. - С. 62. [Kapto AA, Vinogradov IV, Harpunov VF, Mamedov RJe. Rentgenjendovaskuljarnaja angioplastika i stentirovanie u muzhchiny

Сведения об авторах:

Александр Александрович Қапто - канд. мед. наук, заведующий кафедрой урологии, АНО ДПО «Центр обучения медицинских работников», Москва; доцент кафедры урологии с курсами онкологии, радиологии и андрологии, ФГАОУ ВО «Российский университет дружбы народов» Министерства науки и высшего образования Российской Федерации, Москва; руководитель Центра андрологии, многопрофильный медицинский холдинг «СМ-Клиника», Москва. E-mail: alexander_kapto@mail.ru.

Зоя Владиславовна Смыслова - канд. мед. наук, ассистент кафедры педиатрии, ФГАОУ ВО «Российский университет дружбы народов» Министерства науки и высшего образования Российской Федерации, Москва; директор АНО ДПО «Центр обучения медицинских работников», Москва. E-mail: smyslova.zv@smpost.ru. pri May-Thurner syndrome. In: Sbornik tezisov 12-go Kongressa Professional'noj Associacii Andrologov Rossii; date 2017 May 24-27. Sochi, Dagomys; 2017. P. 62. (In Russ.)]

29. Stern JR, Patel VI, Cafasso DE, et al. Left-sided varicocele as a rare presentation of May-Thurner syndrome. Ann Vasc Surg. 2017;42:305. https://doi.org/10.1016/j.avsg.2016.12.001.

30. Keller JJ, Chen YK, Lin HC. Varicocele is associated with erectile dysfunction: a population-based case-control study. J Sex Med. 2012;9(7): 1745-52. https://doi.org/10.1111/.j.1743-6109.2012.02736.x.

31. Maiza D, Courtheoux P, Henriet JP, et al. [Preliminary results 6 months after embolization of the deep dorsal vein of the penis in erectile insufficiencies of venous origin. (In French)]. J Mal Vasc. 1984;9(4):327.

32. Maiza D, Courthéoux $P$, Henriet JP, et al. [Initial results at 6 months of the embolization of the deep dorsal vein of the penis in erectile insufficiencies of venous origin. (In French)]. J Mal Vasc. 1985;10(2):159.

33. Courthéoux P, Maiza D, Henriet JP, et al. [Correction des insuffisances erectiles d'origine veineuse par ballonnets largables et coils. (In French).]. J Radiol. 1985;66:535-359.

34. Courthéoux P, Maiza D, Henriet JP, et al. Erectile dysfunction caused by venous leakage: treatment with detachable balloons and coils. Radiology. 1986;161(3):807-809. https://doi.org/10.1148/ radiology.161.3.3786738.

35. Bookstein JJ, Lurie AL. Transluminal penile venoablation for impotence: a progress report. Cardiovasc Intervent Radiol. 1988;11(4):253-260. https://doi.org/10.1007/bf02577012.

36. Schild HH, Müller SC, Mildenberger $P$, et al. Percutaneous penile venoablation for treatment of impotence. Cardiovasc Intervent Radiol. 1993;16(5):280-286. https://doi.org/10.1007/bf02629158.

37. Капто А.А., Колединский А.Г. Эмболизация вен простатического сплетения в лечении веногенной эректильной дисфункции (клинические случаи) // Экспериментальная и клиническая урология. - 2019. - № 1. - С. 90-94. [Kapto AА, Koledinsky AG. Embolization of the veins of the prostatic plexus in the treatment of venous erectile dysfunction (clinical cases). Experimental and clinical urology. 2019;(1):90-94. (In Russ.)]. https://doi.org/10.29188/2222-8543-2019-11-1-90-94.

Information about the authors:

Alexandr A. Kapto - Candidate of Medical Science, Head of the Department of Urology of the Education Center of Medical Workers, Moscow, Russia; Associate Professor of the Department of Urology with Courses of Oncology, Radiology and Andrology of RUDN University of the Ministry of Science and Higher Education of the Russian Federation, Moscow; Head of the Andrology Center of the Multidisciplinary Medical Holding "SM-Clinic", Moscow, Russia. E-mail: alexander_kapto@mail.ru.

Zoja V. Smyslova - Candidate of Medical Science, Assistant of the Department of Pediatrics of RUDN University of the Ministry of Science and Higher Education of the Russian Federation, Moscow; Director of the Education Center of Medical Workers, Moscow, Russia. E-mail: smyslova.zv@smpost.ru. 